\title{
IMPROVEMENT OF THE PROCEDURE OF MODE PARAMETER CALCULATION FOR GAS-SHIELDED MULTIPASS WELDING
}

\author{
D.S. BUZORINA ${ }^{1,2}$, M.A. SHOLOKHOV ${ }^{2}$ and M.P. SHALIMOV ${ }^{1}$ \\ ${ }^{1}$ Ural Federal University \\ 19 Mira Str., 62002, Ekaterinburg, RF \\ ${ }^{2}$ SHTORM Ltd. \\ 115 Narodnoj Voli Str., Ekaterinburg, RF. E-mail: ekb@shtorm-its.ru
}

\begin{abstract}
Application of automatic and robotic welding systems in modern welding fabrication requires development of algorithms for welding mode parameter control, namely parameter assigning and adaptive correction, depending on conditions. In addition to the main parameters of welding mode (welding current, voltage, speed) and groove geometry, electrode extension and shielding gas composition also have their effect on parameters, determining weld formation and effectiveness of using arc thermal energy for welded joint formation. Dependences of bead cross-sectional area and total thermal efficiency of welding process on electrode extension and shielding gas composition were experimentally established. These dependences were taken into account when improving the earlier developed procedure for calculation of welding mode parameters. Equations take into account both the technological parameters (groove angle, electrode position in the groove, welding speed), and shielding gas composition and electrode extension. 7 Ref., 2 Figures.
\end{abstract}

$\boldsymbol{K} \boldsymbol{e} \boldsymbol{y} \boldsymbol{w} \boldsymbol{o} \boldsymbol{r} \boldsymbol{d} \boldsymbol{s}:$ multipass arc welding, consumable electrode, total thermal efficiency, coefficient of areas, welding mode parameters

In welding technology design an important moment is determination of welding mode parameters, providing welded joints with specified characteristics. Broad application of automatic and robotic welding systems in modern welding fabrication requires development of algorithms of welding mode parameter control, namely assigning and adaptive correction of parameters, depending on conditions. Adaptive correction of welding modes should be based on accurate determination of the influence of each of the process parameters and their combination on weld performance [1]. Most of mathematical models, constructed for welding process control, are based on statistical dependences between energy parameters of welding mode (welding current, arc voltage, speed, etc.) and parameters characterizing welded joint quality (geometrical characteristics, mechanical properties, etc.) [2].

Work [3] proposes a procedure of parameter calculation, which is based on the results of investigation of the influence of technological factors (groove angle $\alpha$, electrode position in the groove $x$, welding speed $v_{\mathrm{w}}$ ) on parameters determining weld formation and effectiveness of arc thermal energy utilization for welded joint formation.
Analysis of literature data showed that in addition to main welding mode parameters (current, voltage, speed) and groove geometry, allowed for in the above-mentioned procedure [3], the studied parameters (bead cross-sectional area and thermal efficiency of welding process) are also influenced by electrode extension [4] and shielding gas composition [4, 5].

It is known that shielding gas composition has a significant influence on technological characteristics and penetration shape. At constant voltage at increase of $\mathrm{CO}_{2}$ fraction up to $50 \%$ in the mixture, the arc becomes shorter, the weld is narrower, penetration depth and bead height become greater, and penetration area increases [4].

Electrode extension in continuous wire welding influences welding process stability. This is due to variation of electrode heating in the extension by passing current. Admissible electrode extension depends on its diameter, specific electric resistance and welding current. At small extensions welding zone visibility is impaired, and partial melting of current conduit is possible, and at large extensions process stability can be disturbed. Extension increase allows increasing the coefficient of electrode melting and reduces penetration depth [4]. By the data of [6] at increase of electrode extension the weld width and penetration depth decrease (all other conditions being equal), and weld convexity becomes greater. Mechanism of electrode extension influence on penetration depth consists in that at in- 
creased extension the amount of deposited metal becomes greater, liquid metal flowing under the arc is intensified; effect of shielding of unmolten base metal by liquid metal interlayer is manifested, leading to shallower penetration of metal being welded [7].

Thus, for practical application of the procedure of calculation of multipass welding mode parameters [3], for instance, in development of algorithms of welding mode parameter control, the equations should allow for both the main process parameters (groove angle, electrode position in the groove, welding speed), and shielding gas composition and electrode extension, which influence weld formation.

The objective of this work is establishing dependences between parameters, characterizing weld formation and welding process parameters, in particular shielding gas composition and electrode extension, as well as determination on the basis of derived dependences of multipass welding mode parameters, ensuring absence of lacksof-fusion.

In the general form equations for determination of bead cross-sectional area and total thermal efficiency can be expressed as follows:

$$
\begin{aligned}
& F=F_{\mathrm{b}}^{v}\left(\alpha, x, v_{\mathrm{w}}\right) \theta_{I}^{F}\left(I_{\mathrm{w}}\right) \theta_{\%}^{F}\left(\% \mathrm{CO}_{2}\right) \theta_{l}^{F}\left(l_{\mathrm{e}}\right), \\
& \eta_{\mathrm{t}}=\eta_{\mathrm{t}}^{v}\left(\alpha, x, v_{\mathrm{w}}\right) \theta_{I}^{\eta}\left(I_{\mathrm{w}}\right) \theta_{\%}^{\eta}\left(\% \mathrm{CO}_{2}\right) \theta_{l}^{\eta}\left(l_{\mathrm{e}}\right),
\end{aligned}
$$

where $F_{\mathrm{b}}^{v}\left(\alpha, x, v_{\mathrm{w}}\right), \eta_{\mathrm{t}}^{v}\left(\alpha, x, v_{\mathrm{w}}\right)$ are the functions of dependence of bead cross-sectional area and thermal efficiency on groove angle, electrode position in the groove, welding speed, respectively, and are found from formulas given in [3]:

$$
\begin{aligned}
F_{\mathrm{b}}= & \left(47.5-0.031 \alpha+4.21 x-0.956 v_{\mathrm{w}}-\right. \\
& -0.113 \alpha x+0.003 \alpha v_{\mathrm{w}}-0.143 x v_{\mathrm{w}}+ \\
& \left.+0.004 \alpha x v_{\mathrm{w}}\right)\left(0.0134 I_{\mathrm{w}}-1.559\right) \\
\eta_{\mathrm{t}}= & \left(0.125-0.006 \alpha+0.018 x+0.024 v_{\mathrm{w}}+\right. \\
+ & 0.00006 \alpha^{2}+0.0006 x^{2}-0.0005 v_{\mathrm{w}}^{2}- \\
& -0.0005 \alpha x+0.00012 \alpha v_{\mathrm{w}}- \\
& \left.-0.00013 x v_{\mathrm{w}}\right)\left(0.0047 I_{\mathrm{w}}+0.084\right)
\end{aligned}
$$

where $F_{\mathrm{b}}$ is the bead cross-sectional area, $\mathrm{mm}^{2}$; $\eta_{\mathrm{t}}$ is the total thermal efficiency of welding process; $\alpha$ is the groove angle, deg; $x$ is the electrode position in the groove, $\mathrm{mm} ; v_{\mathrm{w}}$ is the welding speed, $\mathrm{m} / \mathrm{h} ; I_{\mathrm{w}}$ is the welding current, A; $\theta_{I}^{F}\left(I_{\mathrm{w}}\right), \theta_{\%}^{F}\left(\% \mathrm{CO}_{2}\right), \theta_{l}^{F}\left(l_{\mathrm{e}}\right)$ are the functions of dependence of bead cross-sectional area on welding current, shielding gas composition (percentage of $\mathrm{CO}_{2}$ in $\mathrm{Ar}+\mathrm{CO}_{2}$ mixture) and electrode extension, respectively; $\theta_{I}^{\eta}\left(I_{\mathrm{w}}\right), \theta_{\%}^{\eta}(\% \mathrm{C} \mathrm{Q}), \theta_{l}^{\eta}\left(l_{\mathrm{e}}\right)$ are the functions of dependence of total thermal efficiency of welding process on welding current, shielding gas composition (percentage of $\mathrm{CO}_{2}$ in $\mathrm{Ar}+\mathrm{CO}_{2}$ mixture) and electrode extension, respectively.

A number of experiments were performed to determine functions

$$
\begin{gathered}
\theta_{I}^{F}\left(I_{\mathrm{w}}\right), \theta_{\%}^{F}\left(\% \mathrm{CO}_{2}\right), \theta_{l}^{F}\left(l_{\mathrm{e}}\right), \\
\theta_{I}^{\mathrm{\eta}}\left(I_{\mathrm{w}}\right), \theta_{\%}^{\eta}\left(\% \mathrm{CO}_{2}\right), \theta_{l}^{\eta}\left(l_{\mathrm{e}}\right) .
\end{gathered}
$$

When studying the influence of electrode wire extension and shielding gas composition, the following two assumptions were made: shielding gas composition and electrode wire extension have an influence independent on earlier studied parameters $\left(I, U_{\mathrm{a}}, v_{\mathrm{w}}, x, \alpha\right)$ on bead cross-sectional area and total thermal efficiency of welding process, and shielding gas composition and electrode wire extension do not have any mutual influence on bead cross-sectional area and total thermal efficiency of the welding process.

Experimental data were used to plot graphs of the influence of electrode extension on bead cross-sectional area and on total thermal efficiency of the welding process (Figure 1).

Graphs given in Figure 1, $a$, show that at increase of welding current in the studied range the nature of bead cross-sectional area dependence on electrode extension practically does not change. Therefore, at determination of $F_{\mathrm{b}}$ the earlier assumption of absence of mutual influence
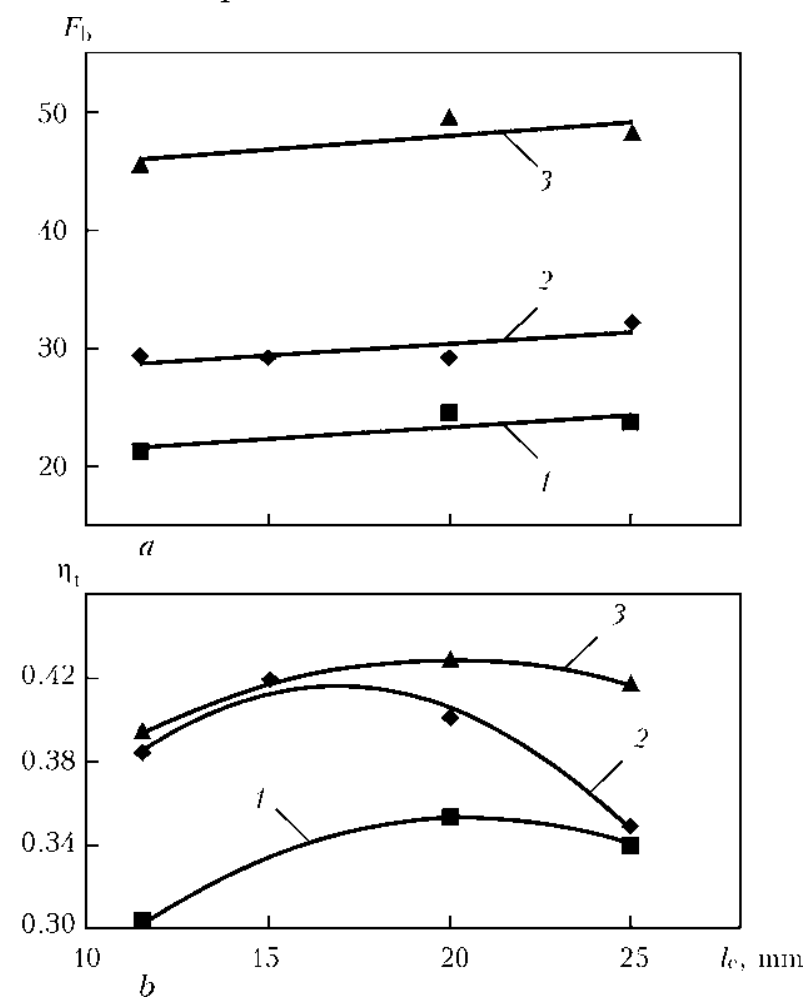

Figure 1. Influence of electrode extension on bead crosssectional area $(a)$ and on total thermal efficiency of welding process $(b): 1-180 ; 2-220 ; 3-260$ A 
of $l_{\mathrm{e}}$ and $I_{\mathrm{w}}$ on $F_{\mathrm{b}}$ can be taken. After processing experimental results, the function of dependence of bead cross-sectional area on electrode extension can be written in the following form:

$$
\theta_{l}^{F}\left(l_{\mathrm{e}}\right)=0.001 l_{\mathrm{e}}+0.956 .
$$

Another shape of the dependence is observed at consideration of the influence of electrode extension on total thermal efficiency of the welding process (Figure 1, b). Analysis of the derived results shows that at increase of welding current the nature of electrode extension influence on total thermal efficiency changes, and, therefore, a conclusion can be made about mutual influence of $l_{\mathrm{e}}$ and $I_{\mathrm{w}}$ on $\eta_{\mathrm{t}}$ of the welding process. Function $\theta_{l}^{\eta}\left(l_{\mathrm{e}}\right)$ can be presented in the form of a quadratic polynomial of two arguments $\left(I_{\mathrm{w}}, l_{\mathrm{e}}\right)$, and after processing experimental data by regression analysis it is expressed as follows:

$$
\begin{aligned}
& \theta_{l}^{\mathrm{\eta}}\left(l_{\mathrm{e}}\right)=-I_{\mathrm{w}}^{2} \cdot 10^{-4}-0.001 l_{\mathrm{e}}^{2}+ \\
& +0.05 I_{\mathrm{w}}+0.03 l_{\mathrm{e}}-3.98 .
\end{aligned}
$$

Figure 2 shows the response surface of function $\theta_{l}^{\eta}\left(l_{\mathrm{e}}\right)$, depending on welding current and electrode extension.

Derived results and data presented provide indirect confirmation of earlier conclusions [3] about complex mutual influence of welding mode parameters on weld formation. There exists a combination of factors providing maximum effective application of arc energy.

When studying the shielding gas composition, it was found that at increase of $\mathrm{CO}_{2}$ fraction in shielding gas mixtures (from 0 up to $30 \%$ ) bead cross-sectional area becomes greater. In this case, increase of bead cross-sectional area is due to enlargement of penetration area, that is in agreement with the known literature data [5].

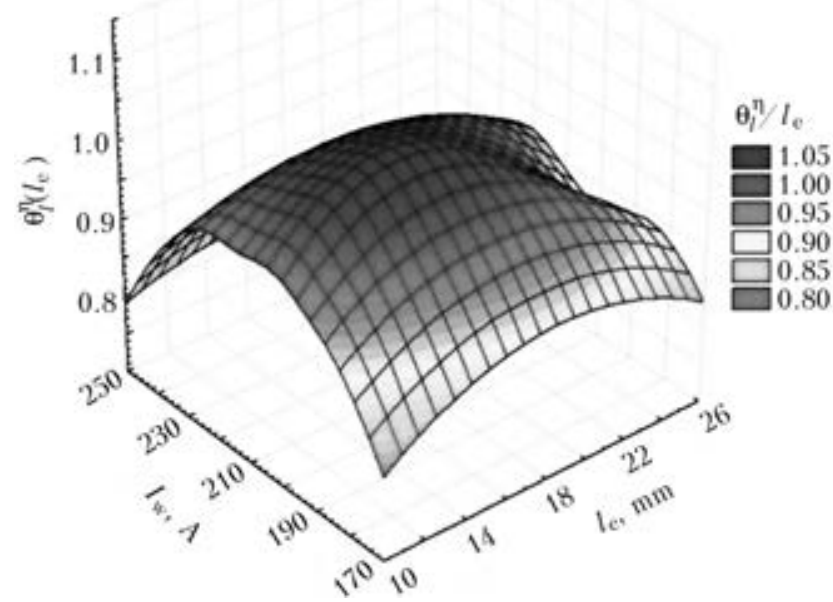

Figure 2. Response surface of function $\theta_{l}^{\eta}\left(l_{\mathrm{e}}\right)$ depending on welding current and electrode extension
Processing of experimental results yielded functions of dependence of bead cross-sectional area and thermal efficiency on $\mathrm{CO}_{2}$ percentage, respectively:

$$
\begin{aligned}
& \theta_{\%}^{F}\left(\% \mathrm{CO}_{2}\right)=0.003 \cdot \% \mathrm{CO}_{2}+0.945, \\
& \theta_{\%}^{\eta}\left(\% \mathrm{CO}_{2}\right)=0.003 \cdot \% \mathrm{CO}_{2}+0.907 .
\end{aligned}
$$

Then general equations (3) and (4) will become:

$$
\begin{aligned}
F= & \left(47.5-0.03 \alpha+4.21 x-0.96 v_{\mathrm{w}}-0.113 \alpha x+\right. \\
& \left.+0.003 \alpha v_{\mathrm{w}}-0.143 x v_{\mathrm{w}}+0.004 \alpha x v_{\mathrm{w}}\right) \times \\
& \times\left(0.013 I_{\mathrm{w}}-1.56\right)\left(0.001 l_{\mathrm{e}}+0.956\right) \times \\
& \times\left(0.003 \cdot \% \mathrm{CO}_{2}+0.945\right), \\
\eta_{\mathrm{t}} & =\left(0.125-0.006 \alpha+0.018 x+0.024 v_{\mathrm{w}}+\right. \\
+ & 0.00006 \alpha^{2}+0.0006 x^{2}-0.0005 v_{\mathrm{w}}^{2}-0.0005 \alpha x+ \\
& \left.+0.00012 \alpha v_{\mathrm{w}}-0.00013 x v_{\mathrm{w}}\right)\left(0.005 I_{\mathrm{w}}+\right. \\
& +0.084)\left(-I_{\mathrm{w}}^{2} \cdot 10^{-4}-0.001 l_{\mathrm{e}}^{2}+0.05 I_{\mathrm{w}}+\right. \\
& \left.+0.03 l_{\mathrm{e}}-3.98\right)\left(0.003 \% \mathrm{CO}_{2}+0.907\right) .
\end{aligned}
$$

Considering the dependences earlier proposed by authors in [3] and derived in this work, dependences of bead cross-sectional area and thermal efficiency on electrode extension (5), (6) and $\mathrm{CO}_{2}$ percentage (7), (8), equations for determination of welding mode parameters can be presented as follows:

- welding current:

$$
I_{\mathrm{w}}=\frac{-b+\sqrt{b^{2}-4 a c}}{2 a}, \mathrm{~A} ;
$$

- coefficients $a, b$ and $c$ are found from formulas

$$
\begin{gathered}
a=-0.015 \frac{\pi d^{2}}{F_{\mathrm{d}}}, \\
b=0.64+0.06 x+\frac{\pi d^{2}}{F_{\mathrm{d}}}(3.34+0.35 x-0.01 \alpha), \\
c=-74.05+0.05 \alpha-6.56 x- \\
-\frac{\pi d^{2}}{F_{\mathrm{d}}}(185.97-0.6 \alpha x-0.58 \alpha+27.81 x)- \\
-\frac{(1+\kappa) F_{\mathrm{d}}}{\left(0.001 l_{\mathrm{e}}+0.956\right)\left(0.003 \cdot \% \mathrm{CO}_{2}+0.945\right)},
\end{gathered}
$$

where $d$ is the electrode diameter, $\mathrm{mm} ; F_{\mathrm{d}}$ is the deposited metal area, $\mathrm{mm}^{2} ; \kappa$ is the coefficient of areas (in consumable electrode welding in the used modes $\kappa=0.18-4)$;

- voltage

$$
U_{\mathrm{ef}}=\frac{B_{\mathrm{ef}} \mathrm{v}_{\mathrm{w} . \mathrm{f}}}{\eta_{\mathrm{t}} I_{\mathrm{w}}}, \mathrm{V} ;
$$

- value of coefficient $B_{\text {ef }}$ is determined by formula 


$$
B_{\text {ef }}=\gamma_{\mathrm{m}} H_{\mathrm{melt}} \frac{(1+k)}{4} \pi d^{2} ;
$$

- value of thermal efficiency of welding process is found from formula

$$
\begin{gathered}
\eta_{\mathrm{t}}=\left(0.125-0.006 \alpha+0.018 x+0.024 v_{\mathrm{w}}+\right. \\
+0.00006 \alpha^{2}+0.0006 x^{2}-0.0005 v_{\mathrm{w}}^{2}-0.0005 \alpha x+ \\
\left.+0.00012 \alpha v_{\mathrm{w}}-0.00013 x v_{\mathrm{w}}\right)\left(0.0047 I_{\mathrm{w}}+\right. \\
+0.084)\left(-I_{\mathrm{w}}^{2} \cdot 10^{-4}-0.001 l_{\mathrm{e}}^{2}+0.05 I_{\mathrm{w}}+0.003 l_{\mathrm{e}}-\right. \\
\quad-3.98)\left(0.003 \% \mathrm{CO}_{2}+0.91\right)
\end{gathered}
$$

where $\gamma_{\mathrm{m}}$ is the specific metal density, $\mathrm{kg} / \mathrm{m}^{3}$; $H_{\text {melt }}$ is the enthalpy at melting temperature allowing for latent heat of melting, $\mathrm{J} / \mathrm{kg} ; k$ is the fusion coefficient;

- welding speed

$$
v_{\mathrm{w}}=\frac{\pi d^{2}\left(0.078 I_{\mathrm{w}}-8.32\right) \cdot 60}{4 F_{\mathrm{d}}}, \mathrm{m} / \mathrm{h} .
$$

\section{Conclusions}

1. Functions of dependence of welding process thermal efficiency and bead cross-sectional area on electrode extension and shielding gas composition were derived in the analytical form.

2. Derived equations for calculation of parameters of the mode of multipass mechanized gas-shielded welding on the basis of determination of total thermal efficiency of welding process allow calculation of welding modes (with the accuracy of about $12 \%$ ) under the condition of guaranteed penetration (at specified coefficient of areas). These equations allow for both process parameters (groove angle, electrode position in the groove, welding speed), and shielding gas composition and electrode extension. Equations can be applied in development of the technology of multipass welding of carbon, low- and medium-alloyed steels in argon-based mixtures of shielding gases.

1. Poloskov, S.I., Erofeev, V.A., Maslennikov, A.V. (2005) Determination of optimal parameters of automatic orbital welding based on computer modeling. Svarochn. Proizvodstvo, 10, 6-13.

2. Lebedev, V.A. (2011) Control of penetration in mechanized welding and surfacing. Ibid., 1, 3-11.

3. Sholokhov, M.A., Buzorina, D.S. (2013) Calculation of mode parameters of wall bead deposition in downhand multi-pass gas-shielded welding. The Paton Welding J., 7, 61-65.

4. Potapievsky, A.G. (1974) Consumable electrode shielded-gas welding. Moscow: Mashinostroenie.

5. Lashchenko, G.I. (2006) Methods of consumable electrode arc welding. Kiev: Ekotekhnologiya.

6. Zhernosekov, A.M. (2004) Effect of electrode stickout on weld parameters in pulsed-arc welding of steels. The Paton Welding J., 8, 51-52.

7. Berezovsky, B.M. (2003) Mathematical model of arc welding. Vol. 2: Mathematical modeling and optimization of different type weld formation. Chelyabinsk: YuUrGU.

Received 26.02.2014 